St. Norbert College

Digital Commons @ St. Norbert College

Faculty Creative and Scholarly Works

4-20-2016

Mitogenomic sequences support a north-south subspecies

subdivision within Solenodon paradoxus

Adam L. Brandt

Kirill Grigorev

Yashira M. Afanador-Hernández

Liz A. Paullino

William J. Murphy

See next page for additional authors

Follow this and additional works at: https://digitalcommons.snc.edu/faculty_staff_works 


\section{Authors}

Adam L. Brandt, Kirill Grigorev, Yashira M. Afanador-Hernández, Liz A. Paullino, William J. Murphy, Adrell Núñez, Aleksey Komissarov, Jessica R. Brandt, Pavel Dobrynin, David Hernández-Martich, Roberto María, Stephen J. O'Brien, Luis E. Rodríguez, Juan C. Martínez-Cruzado, Taras K. Oleksyk, and Alfred L. Roca 
Mitochondrial DNA, Original Article

Title: Mitogenomic sequences support a north-south subspecies subdivision within Solenodon paradoxus

Authors: Adam L. Brandt ${ }^{1,2+}$, Kirill Grigorev ${ }^{4+}$, Yashira M. Afanador-Hernández ${ }^{4}$, Liz A. Paulino $^{5}$, William J. Murphy ${ }^{6}$, Adrell Núñez ${ }^{7}$, Aleksey Komissarov ${ }^{8}$, Jessica R. Brandt ${ }^{1}$, Pavel Dobrynin ${ }^{8}$, J. David Hernández-Martich ${ }^{9}$, Roberto María ${ }^{7}$, Stephen J. O’Brien ${ }^{8,10}$, Luis E. Rodríguez ${ }^{5}$, Juan C. Martínez-Cruzado ${ }^{4}$, Taras K. Oleksyk ${ }^{4 *}$ and Alfred L. Roca $^{1,2,3 *}$

${ }^{+}$Equal contributors

*Corresponding authors: roca@illinois.edu; taras.oleksyk@upr.edu

Affiliations: ${ }^{1}$ Department of Animal Sciences, ${ }^{2}$ Illinois Natural History Survey and ${ }^{3}$ Carl R. Woese Institute for Genomic Biology, University of Illinois at Urbana-Champaign, Urbana, IL 61801; ${ }^{4}$ Department of Biology, University of Puerto Rico at Mayagüez, Mayagüez, Puerto Rico 00681; ${ }^{5}$ Instituto Tecnológico de Santo Domingo (INTEC), Santo Domingo, Dominican Republic; ${ }^{6}$ Department of Veterinary Integrative Biosciences, Texas A\&M University, College Station, TX 77843; ${ }^{7}$ Department of Conservation and Science, Parque Zoológico Nacional (ZOODOM), Santo Domingo, Dominican Republic; ${ }^{8}$ Theodosius Dobzhansky Center for Genome Bioinformatics, St. Petersburg State University, 199004 St. Petersburg, Russia; ${ }^{9}$ Instituto de Investigaciones Botanicas y Zoologicas, Universidad Autónoma de Santo Domingo, Santo Domingo, Dominican Republic; ${ }^{10}$ Oceanographic Center, Nova Southeastern University, Fort Lauderdale, Florida 33004

Corresponding address:

Alfred L. Roca, Ph.D.

Department of Animal Sciences

University of Illinois at Urbana-Champaign

432 ASL, 1207 West Gregory Drive

Urbana, Illinois 61801

Email: roca@illinois.edu

Mobile phone: $240-422-2493$

Office phone: $217-244-8853$

Department fax: 217-333-8286 


\section{Abstract}

43 Solenodons are insectivores found only in Hispaniola and Cuba, with a Mesozoic

44 divergence date versus extant mainland mammals. Solenodons are the oldest lineage of

45 living eutherian mammal for which a mitogenome sequence has not been reported. We

46 determined complete mitogenome sequences for six Hispaniolan solenodons (Solenodon

47 paradoxus) using next generation sequencing. The solenodon mitogenomes were $16,454-$

$48 \quad 16,457 \mathrm{bp}$ long and carried the expected repertoire of genes. A mitogenomic phylogeny

49 confirmed the basal position of solenodons relative to shrews and moles, with solenodon

50 mitogenomes estimated to have diverged from those of other mammals ca. 78 Mya.

51 Control region sequences of solenodons from the northern $(n=3)$ and southern $(n=5)$

52 Dominican Republic grouped separately in a network, with $\mathrm{F}_{\mathrm{ST}}=0.72(\mathrm{p}=0.036)$ between

53 north and south. This regional genetic divergence supports previous morphological and

54 genetic reports recognizing northern (S. p. paradoxus) and southern (S. p. woodi)

55 subspecies in need of separate conservation plans.

58 Key words [3-6]: conservation, Dominican Republic, evolutionarily significant units,

59 Solenodon paradoxus, subspecies, taxonomy 
Introduction

62 Solenodons are fossorial insectivores that live only in the islands of Cuba and

63 Hispaniola (Ottenwalder 1985). The two species of solenodon are among the few native

64 non-volant mammals to survive human colonization of the West Indies (MacPhee et al.

65 1999; Ottenwalder 2001). The geographic range of the Cuban solenodon (Solenodon

66 cubanus Peters, 1861) is currently limited to eastern Cuba (Ottenwalder 1985). The

67 Hispaniolan solenodon (S. paradoxus Brandt, 1833) lives only in the island of

68 Hispaniola, with surviving range primarily within the Dominican Republic (Ottenwalder

69 1985), but with a small remnant population in Haiti (Turvey et al. 2008). Solenodons

70 inhabit the forests of Cuba and Hispaniola to elevations of $2000 \mathrm{~m}$ or more (Eisenberg

71 and Gozalez Gotera 1985; Ottenwalder 1985) and shelter in caves, crevices, logs, and

72 extensive tunnel networks at a depth of $>20 \mathrm{~cm}$ (Eisenberg and Gozalez Gotera 1985;

73 Ottenwalder 1985). They subsist on small vertebrates and large invertebrates (Eisenberg

74 and Gozalez Gotera 1985; Ottenwalder 1985). Solenodons are one of the few mammals

75 that are venomous (Turvey 2010; Folinsbee 2013), and some have argued that they may

76 use a form of echolocation (Eisenberg and Gould 1966).

77 Among hundreds of lineages of recent West Indian tetrapods (mammals, birds,

78 reptiles and amphibians), Solenodon is the only lineage for which strong evidence

79 supports Mesozoic divergence when compared to the closest related living mainland taxa

80 (Roca et al. 2004; Meredith et al. 2011). Most other lineages in the West Indies are

81 known to have diverged from mainland forms in the Cenozoic (Hedges 1996; Woods and

82 Sergile 2001; Roca et al. 2004). In a previous study using 16 nuclear and 3 mitochondrial 
83 genes, solenodons proved to be the earliest branching lineage within Eulipotyphla, or true

84 insectivores (Roca et al. 2004). Contrary to the expectations of some previous

85 morphological studies, solenodons were basal to soricids (shrews), talpids (moles) and

86 erinaceids (hedgehogs and gymnures) (McDowell 1958; Butler 1988; MacPhee and

87 Novacek 1993; McKenna and Bell 1997). The divergence date for solenodons from other

88 eulipotyphlan insectivores has been estimated as 76 million years ago (Mya; 95\%

89 credibility interval [CI] of 72-81 Mya), older than some interordinal splits among

90 mammals (Meredith et al. 2011). This point estimate is before the Cretaceous/Tertiary

91 boundary, with the $95 \%$ CI for the solenodon divergence falling entirely within the

92 Mesozoic Era (Hedges 1996; Iturralde-Vinent and MacPhee 1999; Roca et al. 2004;

93 Meredith et al. 2011).

94 Despite their unique status among mammals (Roca et al. 2004; Wible 2008), until

95 recently only a few studies had published on their DNA, these involving one or a few

96 specimens (Stanhope et al. 1998; Emerson et al. 1999; Allard et al. 2001; Waddell and

97 Shelley 2003; Roca et al. 2004). Likewise, solenodons are the only major mammalian

98 lineage for which the full length of the mitochondrial DNA genome has not been

99 sequenced. Both solenodon species are listed as endangered and declining in population

100 by the IUCN Red List of threatened species (IUCN 2013). Solenodons are currently

101 threatened with extinction due to deforestation, increasing human populations, predation

102 by introduced carnivores, and possibly by competition from introduced rodents

103 (Ottenwalder 1985; Ottenwalder 2001; Borroto-Paez 2009; IUCN 2013; Turvey et al.

104 2014). A better understanding of the genetics of solenodons would assist development of

105 conservation plans. In particular, regional differences in morphology have been reported 
106 in the Hispaniolan solenodon, with specimens from the north of the island (designated as

107 subspecies Solenodon paradoxus paradoxus) larger in size than specimens from the south

108 (designated S. p. woodi) (Ottenwalder 2001). We therefore collected Hispaniolan

109 solenodons from the southern Dominican Republic, and compared their sequences to

110 those of northern solenodons. We also generated the first full mitogenomic sequences

111 reported from both subspecies of Hispaniolan solenodon, filling this gap among

112 mammals, and determining whether the mitogenomic analysis would support a Mesozoic

113 divergence date for the lineage.

\section{Materials and Methods}

\section{Sample collection and DNA extraction}

This study was conducted with the review and approval of the Institutional

120 Animal Care and Use Committee of the University of Puerto Rico. Before the study was

121 conducted, required permits were obtained, including collection and export permits

122 issued by the government of the Dominican Republic, and ESA/CITES and APHIS

123 import permits issued by the US government. For sample Spa-1, collection and DNA

124 extraction details have been reported previously (Roca et al. 2004), all other sequences

125 were from samples newly collected in the wild across various localities in the southern

126 Dominican Republic (Table 1, Figure 1). Samples were obtained in accordance with a

127 permit issued by the Dominican Republic Ministry of the Environment and Natural

128 Resources. As a general protocol, the individuals were captured, weighed, measured, 
129 sexed and immediately released at the capture site, all within ten minutes of capture. A

130 general visual assessment was performed looking for any sign of possible disease. As a

131 general rule, the blood volume collected did not exceed more than $1 \%$ of body weight of

132 animals with no visible sign of distress or disease. Aseptic technique was performed

133 previous to blood draw using a povidone-iodine solution, followed by isopropyl alcohol.

134 Whole blood was collected from the vena jugularis using a $3 \mathrm{~mL}$ syringe with a $23 \mathrm{G} \times 1$ "

135 needle. Once collected, the samples were transferred to a micro-blood collection tube

136 with anticoagulant (BD Microtainer, $1.0 \mathrm{mg}$ K2EDTA for $250-500 \mu \mathrm{L}$ volume). The

137 specimens were then labeled on their tail with a marker to avoid recapturing. Geographic

138 coordinates were recorded for every location where a specimen was captured (Table 1).

139 Tubes were refrigerated until DNA could be extracted from samples using the DNeasy

140 Blood \& Tissue kit (Qiagen, Hilden, Germany).

142 Mitogenome sequence generation, assembly and annotation

$143 \quad$ For each of six individuals of S. paradoxus, a mitogenome was assembled

144 independently from Illumina WGS reads. From northern solenodon (S. p. paradoxus)

145 Spa-1, a total of 52,358,830 paired-end reads were generated, equating to approximately

$14613.09 \mathrm{~Gb}$ of sequence data. For five southern solenodons (S. p. woodi), an average of

$147151,783,327$ paired-end reads were generated, equating to an average of $15.33 \mathrm{~Gb}$ of

148 sequence data for each individual. For each of the six individuals, a mitogenome was

149 assembled independently using two methods. First via a standard approach with MITO-

150 bim (Hahn et al. 2013) using the complete mitochondrial genome sequence of Tapirus

151 indicus (GenBank accession number NC_023838) as a reference seed. Separately, they 
152 were also assembled using a Bruijn graph based algorithm that considers coverage, based

153 on the software Cookiecutter (Starostina et al. 2015). Both produced identical results

154 outside of the control region and open reading frames were present in all coding regions

155 which might otherwise indicate assembly of numts (Lopez et al. 1994). The second

156 software was helpful for excluding reads of unusually low coverage that were almost

157 certainly numts, allowing accurate assembly even for the control region.

$158 \quad$ Complete mitogenome sequences were assembled separately for each individual.

159 Multiple sequence alignment with MAFFT (Katoh and Standley 2013) and a custom

160 variant calling script were employed to assess variation among mitogenomes. This

161 variation was confirmed by aligning reads from every individual to the assembly of every

162 other individual with Bowtie2 (Langmead and Salzberg 2012) and calling variants with

163 SAMtools and Bcftools (Li 2011). All solenodon mitogenomes reported in this study

164 were annotated and deposited in GenBank (accession numbers KU697358-KU697363).

165 Partial mitogenome sequences previously published for S. cubanus (Roca et al. 2004)

166 were likewise aligned to the consensus sequence with MAFFT (Katoh and Standley

167 2013), and variants were called.

168 Protein coding gene discovery and annotation for the consensus sequence of $S$.

169 paradoxus woodi was performed with NCBI ORF Finder (Wheeler et al. 2003) and NCBI

170 Blast (Altschul et al. 1990); rRNA gene discovery and annotation were performed with

171 Barrnap (github.com/tseemann/barrnap). The tRNA gene discovery and annotation was

172 performed with tRNAscan SE (Schattner et al. 2005), with 21 of the 22 tRNA coding

173 genes discovered using relaxed models in tRNAscan and Cove for mitochondrial

174 sequences, with a Cove score cutoff of 10 and intermediate score cutoff of 5. The gene 
175 for tRNA-Ser, expected at approximately the 11.5 kilobase mark, was not discovered

176 with this method. We used Exonerate (Slater and Birney 2005) with the ungapped model

177 to align tRNA coding genes of Sorex araneus (NCBI accession number NC_027963) to

178 the mitogenome of Solenodon paradoxus woodi. All of these aligned to the previously

179 discovered regions, with eight (for Ile, Gln, Ala, Asn, His, Ser, Leu, Pro) alignments

180 spanning their entire lengths, including the previously missed tRNA-Ser at bases 11632

181 11690. The structure and polymorphisms of the mitogenomes and of mtDNA segments

182 were visualized using the software Circos (Krzywinski et al. 2009).

183 To assess amino acid substitutions, pairwise alignments of protein coding regions

184 of S. paradoxus woodi to Talpa europaea (NCBI accession number NC_002391), Sorex

185 araneus (NC_027963), Felis catus (NC_001700) and Homo sapiens

186 (GCA_000001405.20) were performed with the software Exonerate (Slater and Birney

187 2005) model coding2coding. Provean (Choi and Chan 2015) scores were calculated for

188 the substitutions. A stringent score cutoff of -4.1 was used to identify mutations most

189 likely to have effect on protein function; the complete list of these mutations, grouped by

190 genes, is presented in Supplementary Table S1.

192 Phylogenetic analyses and molecular dating

193 For phylogenetic analysis, nucleotide sequences were aligned using webPRANK

194 (Loytynoja and Goldman 2010) in EBI Web Services (McWilliam et al. 2013); alignment

195 output was visually inspected and edited using Mesquite v3.04

196 (http://mesquiteproject.org). Substitution models were determined using the Akaike

197 information criterion in jModeltest2 v 2.1.8 (Darriba et al. 2012). Model testing and 
198 phylogenetic analyses were performed in CIPRES Science Gateway (Miller et al. 2015).

199 Effective sample size values for Markov chain Monte Carlo (MCMC) analyses were

200 verified to be at or above 200 for all parameters. All trees were visualized in FigTree

201 v1.4.2.

202 To examine relationships among the mitogenomes of S. paradoxus, the complete

203 mitogenomic alignment (including control region) of 16,457 bp was used for Bayesian

204 phylogenetic inference (BI) implemented in the program BEAST v1.8.2(Drummond et al.

205 2012), using the HKY substitution model, constant coalescent tree prior, and one of two

206 strict molecular clock rates (fast and slow, respectively): $3.72 \times 10^{-8}$ (Mus musculus)

207 (Goios et al. 2007) or $1.665 \times 10^{-8}$ (Homo sapiens) (Soares et al. 2009) substitutions per

208 site per year. Posterior distributions were obtained by MCMC sampling from at least

$20910,000,000$ steps, with a discarded burn-in of at least 1,000,000; samples were drawn

210 every 1000 MCMC steps.

211 For another analysis, a 2,495 bp alignment of Cuban solenodon (Roca et al. 2004)

212 sequence spanning the $12 \mathrm{~S}$ and $16 \mathrm{~S}$ rRNA regions were aligned to the homologous

213 region of the S. paradoxus mitogenomes used to generate a maximum likelihood (ML)

214 tree in RAxML version 8.2.4 (Stamatakis 2014), using the GTR+I+G substitution model

215 and at least 1000 rapid bootstrap replicates. For additional examination of clades that

216 appeared to correspond to northern and southern geographic localities of S. paradoxus,

217 three previously published control region sequences (Allard et al. 2001) (two northern

218 and one unknown in origin; Figure 1, Table 1) were aligned to the newly generated

219 mitogenomes. A 389 bp alignment of the control region was used for this analysis.

220 Weighted maximum likelihood distances were calculated and used to generate a median 
221 joining network using the software NETWORK v.4.6.1 (Bandelt et al. 2009). Population

222 differentiation ( FST $_{\text {ST }}$ between northern and southern solenodons based on $389 \mathrm{bp}$ of the

223 control region was calculated with ARLEQUIN v.3.5 (Excoffier and Lischer 2010).

224 To place the solenodon into a phylogeny with other mammals, the solenodon

225 mitogenomes (without control region) were aligned to those of the mammals listed in

226 Supplementary Table S2. These included a shrew (Soricidae) and mole (Talpidae),

227 representing the families most closely related to the Solenodontidae, along with 52

228 additional taxa from Laurasiatheria. The mitogenome of the hedgehog, Erinaceus

229 europaeus, was excluded from the analysis due to previously reported (Mouchaty et al.

230 2000) significant deviation of the published mitogenome sequence from expected

231 nucleotide and amino acid compositions. For this analysis, a total of 15,624 aligned

232 nucleotide positions were analyzed after poorly aligned regions (mainly within $12 \mathrm{~S}$ and

233 16S rRNA regions) were excluded. The software RAxML version 8.2.4 (Stamatakis

234 2014) was used to generate a maximum likelihood tree, using the GTR $+\mathrm{I}+\mathrm{G}$ substitution

235 model and 1000 rapid bootstrap replicates.

236 For molecular dating of the split between the Solenodontidae and other

237 laurasiatherian families, fossil calibration dates reported previously (Meredith et al. 2011)

238 were used. These fossil calibration dates are listed in Supplementary Table S3, along with

239 the inferred date estimates for nodes on the mammalian mitogenomic tree. This analysis

240 was performed using BEAST v1.8.2 (Drummond et al. 2012). We utilized an

241 uncorrelated lognormal relaxed molecular clock model, which permits the rate of

242 molecular substitutions to be independent across the tree while incorporating uncertainty

243 in both tree topology and multiple fossil calibrations (Drummond et al. 2012). We used 
244 randomly generated starting trees and birth-death process tree prior (Gernhard 2008). A

245 monophyly constraint was applied to non-eulipotyphlan taxa to minimize spurious dating

246 resulting from incorrect trees and to enforce the correct topology (Eulipotyphla sister to

247 all other laurasiatherians), which has been well established using nuclear data (Roca et al.

248 2004; Meredith et al. 2011). Posterior distributions were obtained by MCMC sampling

249 from at least 60,000,000 steps, with a discarded burn-in of at least 6,000,000; samples

250 were drawn every 1000 MCMC steps.

\section{Results}

The consensus mitogenome of the Hispaniolan solenodon was 16,457 bp, and

255 consists of the expected repertoire of 37 genes, including 13 that code for polypeptides,

25622 for transfer RNA (tRNA) and the small and large subunits of ribosomal RNA (rRNA).

257 The length of the mitogenome was: $16,457 \mathrm{bp}$ for Spa-K; 16,456 bp for Spa-L; 16,455 for

258 Spa-M, $-\mathrm{N}$ and $-\mathrm{O}$; and 16,454 for Spa-1. Figure 2 represents gene and variant tracks

259 plotted with Circos (Krzywinski 2009). The five individuals of S. paradoxus woodi

260 exhibited little sequence variation (Figure 2). Spa-M, -N and -O were identical in

261 sequence. Between Spa-K and Spa-L there were 2 differences. And for Spa-M/N/O there

262 were 4 differences with Spa-K and 2 differences with Spa-L. By contrast, the

263 mitogenome of the individual of S. paradoxus paradoxus (Spa-1) exhibited 100

264 differences from the consensus of the 5 southern solenodons; and the mtDNA fragments

265 of S. cubanus showed an even greater density of differences (Figure 2). Coding genes

266 were discovered and annotated de novo. The relative positions and lengths of the genes in 
267 S. paradoxus closely corresponded to those in the mitogenomes of other laurasiatherian

268 mammals, corroborating the result. Comparison of the amino acid residues of the protein

269 coding genes with those of four other species of eutherian mammals found many

270 substitutions with significant Provean scores. Mutations with Provean scores indicating

271 mutations most likely to have functional effects were grouped by gene, and are presented

272 in Supplementary Table S1. Most of these radical mutations corresponded to changes that

273 had occurred in the solenodon lineage, since the other species all shared the same amino

274 acid at most positions. Most of the radical mutations fell within the genes ND2 and ND5.

275 The complete mitogenomes (including control regions) of Hispaniolan solenodons

276 were used to infer a phylogeny in BEAST. The 5 solenodons from southern Hispaniola

277 formed a clade with the northern Hispaniolan solenodon as an outgroup to the clade

278 (Figure 3A). Using two evolutionary rates (the fast rate of house mouse (Goios et al.

279 2007), $3.72 \times 10^{-8}$ and the slow rate of humans (Soares et al. 2009), $1.665 \times 10^{-8}$

280 substitutions per site per year) as extremes, the point estimate for the divergence between

281 the two clades was estimated as 78,000 and 171,400 years, respectively. Using an

282 alignment of $12 \mathrm{~S}$ and $16 \mathrm{~S}$ rRNA regions for which S. cubanus sequence could be used as

283 an outgroup confirmed that the split in S. paradoxus was between the 5 southern and 1

284 northern Hispaniolan solendons (Figure 3B). In an attempt to increase the number of

285 northern individuals that could be analyzed, the control region sequences of the $S$.

286 paradoxus genomes were aligned with those previously published for three solenodons,

287 two of northern provenance (Loma de la Jagua; Figure 1) and one of unknown origin. In

288 a network analysis of the control region sequences, there was separation between the

289 northern $(\mathrm{n}=3)$ and southern $(\mathrm{n}=5)$ individuals (Figure 3C). For this dataset, FST between 
290 the northern and southern populations was estimated as $0.72477(\mathrm{p}=0.03604)$. It is

291 important to note that although FsT between the northern and southern populations was

292 high, there were only a few mutational steps that differentiated the two populations.

293 Our solenodon mitogenomic sequences (excluding control region) were then

294 aligned with those of 54 other mammalian taxa (Supplementary Table S2). The

295 relationships inferred for the taxa are shown in Supplementary Figures S1 and S2, and

296 confirms that solenodons were basal to soricids and talpids. Relying on well-established

297 fossil calibration dates reported previously (Supplementary Table S3) (Meredith et al.

298 2011), we estimated that solenodons had diverged from other mammals ca. 78.2 Mya

299 (95\% CI of 62.1-98.6 Mya). In this case, the estimated coalescence date for the $S$.

300 paradoxus sequences (north vs. south) was 0.60 (95\% CI of 0.33-0.94) Mya.

301

302 Discussion

303

304 There may be a number of potential caveats when considering the relationships

305 among some taxa or the molecular dating: (1) there is a potential that some published

306 mitogenomic sequences may have unwittingly incorporated numts (Lopez et al. 1994);

307 (2) the analyses may be affected by different evolutionary rates across branches; (3) long

308 branch attraction may potentially affect relationships; (4) various factors may lead to

309 mito-nuclear incongruence, notably hybridization and sex-biased gene flow ( $\mathrm{Li}$ et al.

310 2016). Given those potential caveats, it is noteworthy that using mammalian

311 mitogenomes, the solenodons are estimated to have diverged from other mammals ca.

$31278.2 \mathrm{Mya}(95 \% \mathrm{CI}$ of 62.1-98.6 Mya). This is remarkably close to the previous point 
313 estimate of 76 Mya for divergence initially estimated using primarily nuclear gene

314 sequences (Roca et al. 2004), and to a more recent estimate based on nuclear sequences

315 of 77.3 Mya (95\% CI of 70.7-85.8 Mya) (Meredith et al. 2011).

316 This time estimate would be consistent with a vicariant origin for solenodons,

317 since the proto-Antilles may have been connected to the North American continent some

318 70-80 Mya (Hedges 1996; Iturralde-Vinent and MacPhee 1999; Acton et al. 2000).

319 However, the end of the Cretaceous 65 Mya is marked by the impact of an asteroid at

320 nearby Chicxulub in the Yucatan (Iturralde-Vinent and MacPhee 1999). Small fossorial

321 mammals may be more likely to survive some catastrophic events (Andersen and

322 MacMahon 1985), and it is unlikely that islands of the proto-Antilles were completely

323 inundated by the tsunami caused by the shallow-sea impact (Bryant 2014). Nonetheless,

324 any life in the proto-Antilles would have faced catastrophic effects, especially since the

325 islands would have been even closer to the impact site than they are today (Hedges 1996).

326 Additionally, although some geologists have stated that the mountains of Hispaniola have

327 remained above sea level continuously since the Mesozoic (Donnelly 1992), others have

328 argued that every Caribbean island has been submerged at some point during the

329 Cenozoic (Iturralde-Vinent and MacPhee 1999), which if true would rule out a

330 completely vicariant origin for the solenodon lineage.

331 A Mesozoic divergence date versus other mammals does not necessarily imply a

332 vicariant origin, as the solenodon lineage may have diverged more recently from

333 mainland mammals that are now extinct. Some North American extinct taxa thought to be

334 related to Solenodon, such as Centetodon or Apternodus (Asher et al. 2002; Lopatin

335 2003), did not appear to be close to Solenodon when morphological datasets were 
336 analyzed while constrained to a scaffold tree of known molecular relationships (Asher et

337 al. 2002; Roca et al. 2004). The recently extinct Nesophontidae (Whidden and Asher

338 2001; Rzebik-Kowalska and Woloszyn 2012; Orihuela 2014), a family of 11 species of

339 insectivores that also lived only in the islands of the West Indies but went extinct after

340 European settlement, also did not appear close to solenodons in that analysis. One issue

341 with a dispersal of solenodons into the Antilles is that they are present only in Cuba and

342 Hispaniola, with their origin in the two islands attributed to vicariance, since the

343 divergence time between the two species (Roca et al. 2004) occurred when the two

344 islands separated geologically (Iturralde-Vinent and MacPhee 1999). Since solenodons

345 are also not found in other Caribbean islands, they are unlikely to be natural dispersers.

346 Nesophontes appears to have more regularly dispersed across islands, as species were

347 present in Puerto Rico and the Cayman Islands for which dispersal is the only plausible

348 explanation (Whidden and Asher 2001). Recently, an analysis of endocranial morphology

349 has suggested similarities between Solenodon and Nesophontes (Orihuela 2014). If a

350 sister relationship is upheld between Solenodon and Nesophontes, one can hypothesize

351 that the ancestral form was more likely to resemble Nesophontes, for which there is

352 strong evidence for dispersal, and that the morphology of non-dispersing Solenodon may

353 be derived subsequent to arrival.

$354 \quad$ Based on an examination of 65 southern and 128 northern specimens of $S$.

355 paradoxus, Ottenwalder has proposed placing populations in the Peninsula de Barahona

356 and Sierra de Bahoruco of the southwest Dominican Republic in a distinct subspecies $S$.

357 p. woodi, characterized by its small body size, and into which he also placed the

358 solenodons from Massif de la Hotte in Haiti (Ottenwalder 2001). Solenodons living north 
359 of the Cul de Sac Plain/Neiba Valley (see Figure 1) were placed into the subspecies S. p.

360 paradoxus. These differences were likely due to repeated separation of northern and

361 southern Hispaniola by a marine canal into north and south paleo-islands during the

362 Pliocene and Pleistocene (Ottenwalder 2001). Our results are consistent with the

363 proposed subspecies division, since solenodons from the northern and southern

364 Dominican Republic (Figure 1) separate in a haplotype network (Figure 3C). The

365 southern Hispaniola solenodons appear to have much less genetic diversity than those in

366 the north (Figure 3C), which may be related to the sixfold larger size of the northern

367 paleo-island over the southern paleo-island (Figure 1) (Ottenwalder 2001). The estimated

368 FST of 0.72 between northern and southern populations suggests a high degree of

369 differentiation between the two geographic groups. This division into two subspecies

370 would have needed confirmed by additional sampling and by the use of nuclear genetic

371 markers. As this manuscript was in the peer-review process, a broader survey of

372 solenodons across Hispaniola was reported (Turvey et al. 2016), based on $534 \mathrm{bp}$ of the

373 control region and $411 \mathrm{bp}$ of cytochrome b in 34 samples of Solenodon paradoxus. They

374 report the species to be genetically divided into northern, south-eastern and south-western

375 populations (the last being confined to the Massif de la Hotte in Haiti) (Turvey et al.

376 2016). They also report morphometric support for this subdivision using 110 specimens

377 (Turvey et al. 2016). Our results here thus confirm their finding that the northern and

378 south-eastern populations are distinctive, and that the south-eastern population has very

379 limited mitochondrial DNA diversity, and provide further support for the conservation

380 management of Hispaniolan solenodons as distinct regional subspecies or evolutionarily

381 significant units. 


\section{Acknowledgements}

384

385 We thank Nicolas Corona and Yimell Corona for assistance in collecting samples.

386

387 Declaration of Interest Statement

388

389 The authors have declared that there is no conflict of interest.

390

391 Funding

392

393 SJO, AK, and PD were supported by the Russian Ministry of Science Mega-grant

394 no.11.G34.31.0068.

395

396

397 References

398

399 Acton GD, Galbrun B, King JW. 2000. Paleolatitude of the Caribbean Plate since the 400 Late Cretaceous. In: Leckie RM, Sigurdsson H, Acton GD, Draper G, editors. 401 Proc. ODP, Sci. Results. College Station (TX): Ocean Drilling Program. p. 149$402 \quad 173$.

403 Allard MW, Baker SD, Emerson GL, Ottenwalder JA, Kilpatrick CW. 2001.

404 Characterization of the mitochondrial control region of Solenodon paradoxus 
from Hispaniola and the implications for biogeography, systematics, and conservation management. In: Woods CA, Sergile FE, editors. Biogeography of the West Indies: Patterns and Perspectives. 2nd ed. Boca Raton (FL): CRC Press. p. 331-334.

Altschul SF, Gish W, Miller W, Myers EW, Lipman DJ. 1990. Basic local alignment search tool. J Mol Biol. 215:403-10.

411 Andersen DC, MacMahon JA. 1985. The effects of catastrophic ecosystem disturbance:

412 the residual mammals at Mount St. Helens. J Mammal. 66:581-589.

413 Asher RJ, McKenna MC, Emry RJ, Tabrum AR, Kron DG. 2002. Morphology and 414 relationships of Apternodus and other extinct, zalambdodont placental mammals. $415 \quad$ Bul Amer Mus Nat Hist. 217:1-117.

416 Bandelt HJ, Yao YG, Bravi CM, Salas A, Kivisild T. 2009. Median network analysis of 417 defectively sequenced entire mitochondrial genomes from early and contemporary 418 disease studies. J Hum Genet. 54(3):174-81.

419 Borroto-Paez R. 2009. Invasive mammals in Cuba: An overview. Biol Inv. 11(10):2279$420 \quad 2290$.

421 Bryant E. 2014. Tsunami: The Underrated Hazard. 3rd ed. London: Springer.

422 Butler PM. 1988. Phylogeny of the insectivores. In: Benton MJ, editor. The Phylogeny 423 and Classification of the Tetrapods. Oxford: Oxford University Press. p. 117-141.

424 Choi Y, Chan AP. 2015. PROVEAN web server: a tool to predict the functional effect of 425 amino acid substitutions and indels. Bioinformatics. 31(16):2745-7.

426 Darriba D, Taboada GL, Doallo R, Posada D. 2012. jModelTest 2: more models, new 427 heuristics and parallel computing. Nat Methods. 9:772. 
428 Donnelly TW. 1992. Geological setting and tectonic history of Mesoamerica. In:

429 Quintero D, Aiello A, editors. Insects of Panama and Mesoamerica: selected studies. Oxford: Oxford University Press. p. 1-13.

431 Drummond AJ, Suchard MA, Xie D, Rambaut A. 2012. Bayesian phylogenetics with BEAUti and the BEAST 1.7. Mol Biol Evol. 29:1969-1973.

433 Eisenberg JF, Gould E. 1966. The behavior of Solenodon paradoxus in captivity with comments on the behavior of other Insectivora. Zoologica. 51:49-58.

435 Eisenberg JF, Gozalez Gotera N. 1985. Observations on the natural history of Solenodon $436 \quad$ cubanus. Acta Zoolog Fennica. 173:275-277.

437 Emerson GL, Kilpatrick CW, McNiff BE, Ottenwalder J, Allard MW. 1999.

438 Phylogenetic relationships of the order Insectivora based on complete 12S rRNA 439 sequences from mitochondria. Cladistics. 15:221-230.

440 Excoffier L, Lischer HE. 2010. Arlequin suite ver 3.5: a new series of programs to

441 perform population genetics analyses under Linux and Windows. Mol Ecol

$442 \quad$ Resour. 10:564-7.

443 Folinsbee KE. 2013. Evolution of venom across extant and extinct eulipotyphlans.

$444 \quad$ Comptes Rendus Palevol. 12:531-542.

445 Gernhard T. 2008. New analytic results for speciation times in neutral models. Bull Math $446 \quad$ Biol. 70:1082-1097.

447 Goios A, Pereira L, Bogue M, Macaulay V, Amorim A. 2007. mtDNA phylogeny and 448 evolution of laboratory mouse strains. Genome Res. 17:293-298. 
449 Hahn C, Bachmann L, Chevreux B. 2013. Reconstructing mitochondrial genomes directly from genomic next-generation sequencing reads-a baiting and iterative mapping approach. Nucleic Acids Res. 41:e129.

452 Hedges SB. 1996. Historical biogeography of West Indian vertebrates. Annu Rev Ecol 453 Syst. 27:163-196.

454 Iturralde-Vinent MA, MacPhee RDE. 1999. Paleogeography of the Caribbean region: 455 implications for Cenozoic biogeography. Bull Amer Mus Nat Hist. 238:1-238.

456 IUCN. 2013. The International Union for the Conservation of Nature (IUCN) Red List of

457 Threatened Species, 2013.2. http://www.redlist.org.

458 Katoh K, Standley DM. 2013. MAFFT multiple sequence alignment software version 7:

459 improvements in performance and usability. Mol Biol Evol. 30:772-80.

460 Krzywinski M, Schein J, Birol I, Connors J, Gascoyne R, Horsman D, Jones SJ, Marra

461 MA. 2009. Circos: an information aesthetic for comparative genomics. Genome $462 \quad$ Res. 19:1639-45.

463 Langmead B, Salzberg SL. 2012. Fast gapped-read alignment with Bowtie 2. Nat Meth. $464 \quad 9: 357-9$.

465 Li G, Davis BW, Eizirik E, Murphy WJ. 2016. Phylogenomic evidence for ancient 466 hybridization in the genomes of living cats (Felidae). Genome Res. 26:1-11.

467 Li H. 2011. A statistical framework for SNP calling, mutation discovery, association 468 mapping and population genetical parameter estimation from sequencing data.

$469 \quad$ Bioinformatics. 27:2987-2993. 
470 Lopatin AV. 2003. A zalambdodont insectivore of the family Apternodontidae

471 (Insectivora, Mammalia) from the Middle Eocene of Mongolia. Paleontol J.

$472 \quad 37: 187-195$.

473 Lopez JV, Yuhki N, Masuda R, Modi W, O'Brien SJ. 1994. Numt, a recent transfer and 474 tandem amplification of mitochondrial DNA to the nuclear genome of the 475 domestic cat. J Mol Evol. 39(2):174-90.

476 Loytynoja A, Goldman N. 2010. webPRANK: a phylogeny-aware multiple sequence $477 \quad$ aligner with interactive alignment browser. BMC Bioinformatics. 11:579.

478 MacPhee RDE, Flemming C, Lunde DP. 1999. "Last occurrence" of the Antillean 479 insectivoran Nesophontes: new radiometric dates and their interpretation. Amer $480 \quad$ Mus Novit. 3261:1-20.

481 MacPhee RDE, Novacek MJ. 1993. Definitions and relationships of Lipotyphla. In:

482 Szalay FS, Novacek MJ, McKenna MC, editors. Mammal Phylogeny: Placentals. $483 \quad$ New York: Springer-Verlag. p. 13-31.

484 McDowell SB, Jr. 1958. The Greater Antillean insectivores. Bull Amer Mus Nat Hist. $485 \quad 115: 113-214$.

486 McKenna MC, Bell SK. 1997. Classification of Mammals above the Species Level. New $487 \quad$ York: Columbia University Press.

488 McWilliam H, Li WZ, Uludag M, Squizzato S, Park YM, Buso N, Cowley AP, Lopez R. 489 2013. Analysis Tool Web Services from the EMBL-EBI. Nucleic Acids Res. 490 41:W597-W600. 
491 Meredith RW, Janecka JE, Gatesy J, Ryder OA, Fisher CA, Teeling EC, Goodbla A, Eizirik E, Simao TL, Stadler T, et al. 2011. Impacts of the Cretaceous terrestrial revolution and KPg extinction on mammal diversification. Science. 334:521-524.

494 Miller MA, Schwartz T, Pickett BE, He S, Klem EB, Scheuermann RH, Passarotti M, Kaufman S, O'Leary MA. 2015. A RESTful API for access to phylogenetic tools via the CIPRES Science Gateway. Evol Bioinform Online. 11:43-48.

Mouchaty SK, Gullberg A, Janke A, Arnason U. 2000. Phylogenetic position of the tenrecs (Mammalia: Tenrecidae) of Madagascar based on analysis of the complete mitochondrial genome sequence of Echinops telfairi. Zool Scr. 29:307-317. (Lipotyphla: Nesophontidae) from natural and digital endocasts of Cuban taxa.

Ottenwalder J. 2001. Systematics and biogeography of the West Indian genus Solenodon.

504 In: Woods CA, Sergile FE, editors. Biogeography of the West Indies: Patterns and Perspectives. 2nd ed. Boca Raton (FL): CRC Press. p. 253-329.

506 Ottenwalder JA. 1985. The distribution and habitat of Solenodon in the Dominican Republic. [MS Thesis]. Gainesville (FL): University of Florida.

508 Roca AL, Bar-Gal GK, Eizirik E, Helgen KM, Maria R, Springer MS, O'Brien SJ, Murphy WJ. 2004. Mesozoic origin for West Indian insectivores. Nature.

511 Rzebik-Kowalska B, Woloszyn BW. 2012. New data on Nesophontes subfossil 512 populations from Cuba and Isla de la Juventud (Cuba). Neues Jahrbuch für 513 Geologie und Paläontologie. 263:155-166. 
514 Schattner P, Brooks AN, Lowe TM. 2005. The tRNAscan-SE, snoscan and snoGPS web

515 servers for the detection of tRNAs and snoRNAs. Nucleic Acids Res. 33:W686-

$516 \quad$ W689.

517 Slater GS, Birney E. 2005. Automated generation of heuristics for biological sequence

518 comparison. BMC Bioinformatics. 6:31.

519 Soares P, Ermini L, Thomson N, Mormina M, Rito T, Rohl A, Salas A, Oppenheimer S,

520 Macaulay V, Richards MB. 2009. Correcting for purifying selection: an improved

521 human mitochondrial molecular clock. Am J Hum Genet. 84:740-759.

522 Stamatakis A. 2014. RAxML version 8: a tool for phylogenetic analysis and post-analysis

523 of large phylogenies. Bioinformatics. 30:1312-1313.

524 Stanhope MJ, Waddell VG, Madsen O, de Jong W, Hedges SB, Cleven GC, Kao D,

525 Springer MS. 1998. Molecular evidence for multiple origins of Insectivora and for

526 a new order of endemic African insectivore mammals. Proc Natl Acad Sci U S A.

$527 \quad 95: 9967-9972$.

528 Starostina E, Tamazian G, Dobrynin P, O'Brien SJ, Komissarov A. 2015. Cookiecutter: a

529 tool for kmer-based read filtering and extraction. bioRxiv DOI:

$530 \quad$ http://dx.doi.org/10.1101/024679.

531 Turvey ST. 2010. Evolution of non-homologous venom delivery systems in West Indian 532 insectivores. J Vert Paleontol. 30:1294-1299.

533 Turvey ST, Fernández-Secades C, Nuñez-Miño JM, Hart T, Martinez P, Brocca JL,

534 Young RP. 2014. Is local ecological knowledge a useful conservation tool for 535 small mammals in a Caribbean multicultural landscape? Biol Conserv. 169:189-

536197.


537 Turvey ST, Meredith HMR, Scofield RP. 2008. Continued survival of Hispaniolan

538 solenodon Solenodon paradoxus in Haiti. Oryx. 42:611-614.

539 Turvey ST, Peters S, Brace S, Young RP, Crumpton N, Hansford J, Nunez-Mino JM,

$540 \quad$ King G, Tsalikidis K, Ottenwalder JA, et al. 2016. Independent evolutionary

541 histories in allopatric populations of a threatened Caribbean land mammal.

542 Diversity Distrib. DOI: http://dx.doi.org/10.1111/ddi.12420

543 Waddell PJ, Shelley S. 2003. Evaluating placental inter-ordinal phylogenies with novel

$544 \quad$ sequences including RAG1, gamma-fibrinogen, ND6, and mt-tRNA, plus

545 MCMC-driven nucleotide, amino acid, and codon models. Mol Phylogenet Evol.

$546 \quad 28: 197-224$.

547 Wheeler DL, Church DM, Federhen S, Lash AE, Madden TL, Pontius JU, Schuler GD,

548 Schriml LM, Sequeira E, Tatusova TA et al. 2003. Database resources of the

549 National Center for Biotechnology. Nucleic Acids Res. 31:28-33.

550 Whidden HP, Asher RJ. 2001. The origin of the Greater Antillean insectivorans. In:

551 Woods CA, Sergile FE, editors. Biogeography of the West Indies: Patterns and

552 Perspectives. 2nd ed. Boca Raton (FL): CRC Press. p. 237-252.

553 Wible JR. 2008. On the cranial osteology of the Hispaniolan Solenodon, Solenodon

554 paradoxus Brandt, 1833 (Mammalia, Lipotyphla, Solenodontidae). Ann Carnegie

$555 \quad$ Mus. 77:321-385.

556 Woods CA, Sergile FE. 2001. Biogeography of the West Indies: Patterns and

557 Perspectives. Boca Raton (FL): CRC Press.

558

559 


\section{$560 \quad$ Figure Legends}

561

562 Figure 1. Elevation map of Hispaniola showing sampling localities. Hispaniolan

563 solenodon mtDNA sequences were from samples from the localities indicated, in both the

564 southern and northern Dominican Republic (DR). From the southern DR, in the Province

565 of Pedernales, La Cañada del Verraco and two collection points in El Manguito were

566 sampled for the current study. Novel mitogenomic sequences were also obtained from a

567 sample previously collected from the Cordillea Septentrional in the Province of Espaillat

568 in the northern DR (Roca et al. 2004). Also included in some analyses were previously

569 generated mtDNA sequences (Emerson et al. 1999; Allard et al. 2001) from two

570 specimens from Loma de la Jagua, Cabrera Promontory, Province of Maria Trinidad

571 Sanchez in the northern DR; a third mtDNA sequence from the same study was from a

572 specimen of unknown provenance. The key for elevation above sea level is shown; the

573 darkest shaded regions have the lowest elevation. The dashed line shows the position of

574 the Cul de Sac Plain and Neiba Valley; this region was periodically inundated by a

575 marine canal that separated Hispaniola into north and south paleo-islands during the

576 Pliocene and Pleistocene (Ottenwalder 2001). The original map courtesy of NASA is in

577 the public domain.

578

579 Figure 2. Structure and variation in the mitogenomes of Solenodon. The thicker gray

580 circle shows the location of genes and the control region of a consensus of the 5

581 mitogenomes of individuals from the south, with the positions of the rRNA genes (red),

582 protein coding genes (blue), tRNA genes (orange) and control region (green) indicated. 
583 Genome coordinates are in kilobases. The inner gray semi-circles indicate mitogenomic

584 variation among solenodons from the southern Dominican Republic (subspecies $S$.

585 paradoxus woodi) when compared to the consensus. Spa-K and $-\mathrm{L}$ are from La Cañada

586 del Verraco, while Spa-M, -N and -O are from nearby El Manguito. Very little variation

587 is seen among these solenodons from southern Hispaniola. By contrast, the mitogenome

588 of a solenodon from northern Hispaniola (subspecies S. paradoxus paradoxus),

589 designated Spa-1, shows much higher variability when compared to the southern

590 consensus sequence. At the top of the figure, fragments of mtDNA previously reported

591 (Roca et al. 2004) for the Cuban solenodon (S. cubanus) show even greater variation

592 relative to the reference mitogenome; insertions are shown as cut-ins on the tracks.

593

594 Figure 3. Relationship among Hispaniolan solenodons (S. paradoxus) from different

595 geographic regions. (A) Phylogeny generated using the full mitogenomic sequences,

596 including the control region (16,457 bp). Individuals are identified by sample number for

597 solenodons captured in the north $(\mathrm{N})$ and south (S) of Hispaniola. The divergence date of

598 nodes was estimated using the rate observed in humans. Coalescence dates (in thousands

599 of years, with $95 \%$ CI) are indicated at the nodes with a chronogram below the tree. (B)

600 In order to root the tree, novel mtDNA sequences from S. paradoxus were aligned to a

601 previously reported 2,495 bp sequence of the Cuban solenodon (S. cubanus), which was

602 used as an outgroup (GenBank accession AY530083) (Roca et al. 2004). The root

603 separated the single northern Hispaniolan solenodon (Spa-1) from five southern

604 Hispaniolan solenodons. (C) To examine whether mitochondrial sequences of

605 Hispaniolan solenodons are different in the north and south of Hispaniola, the novel 
606 sequences were combined in a $389 \mathrm{bp}$ alignment with previously generated control region

607 sequences from two specimens from the northern Dominican Republic, and one of

608 unknown provenance. The network shows each difference as a hatch mark (all were

609 substitutions, there were no indels). The control region sequences from the 5 southern

610 specimens were identical and at one end of the network, separated from the sequences of

611 northern Hispaniolan solenodons. The separation of northern and southern haplotypes is

612 consistent with a previous suggestion, based on morphological measurements, that $S$.

613 paradoxus be subdivided into a northern (S. p. paradoxus) and a southern (S. p. woodi)

614 subspecies (Ottenwalder 2001).

615 
This is an Accepted Manuscript of an article published by Taylor \& Francis Group in Mitochondrial DNA Part A on 15/03/2016, available online: http://dx.doi.org/10.3109/24701394.2016.1167891.

616

[[Figure 1]]

617

618

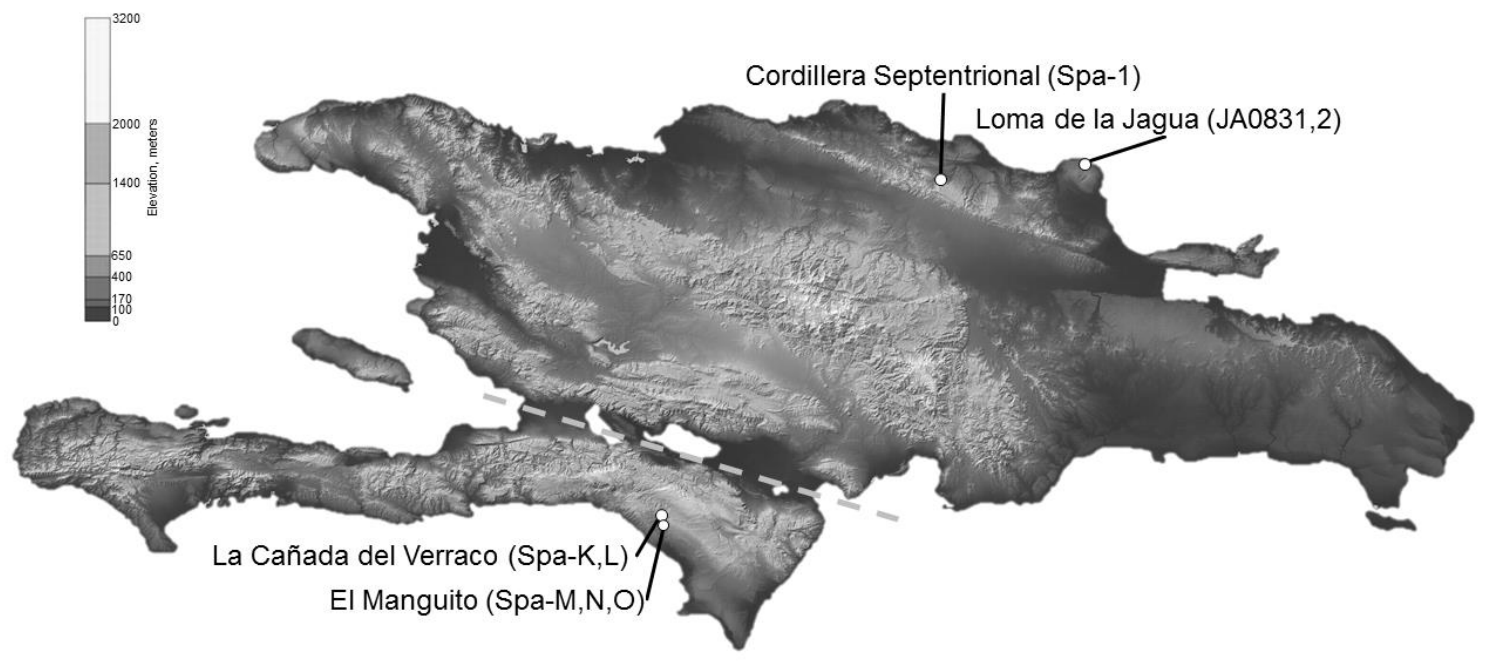


This is an Accepted Manuscript of an article published by Taylor \& Francis Group in Mitochondrial DNA Part A on 15/03/2016, available online: http://dx.doi.org/10.3109/24701394.2016.1167891.

\begin{tabular}{l}
\hline Gene track: \\
rRNA genes \\
Protein coding genes \\
tRNA genes \\
Control region \\
Variant tracks: \\
A C C G \\
deletion I I
\end{tabular}
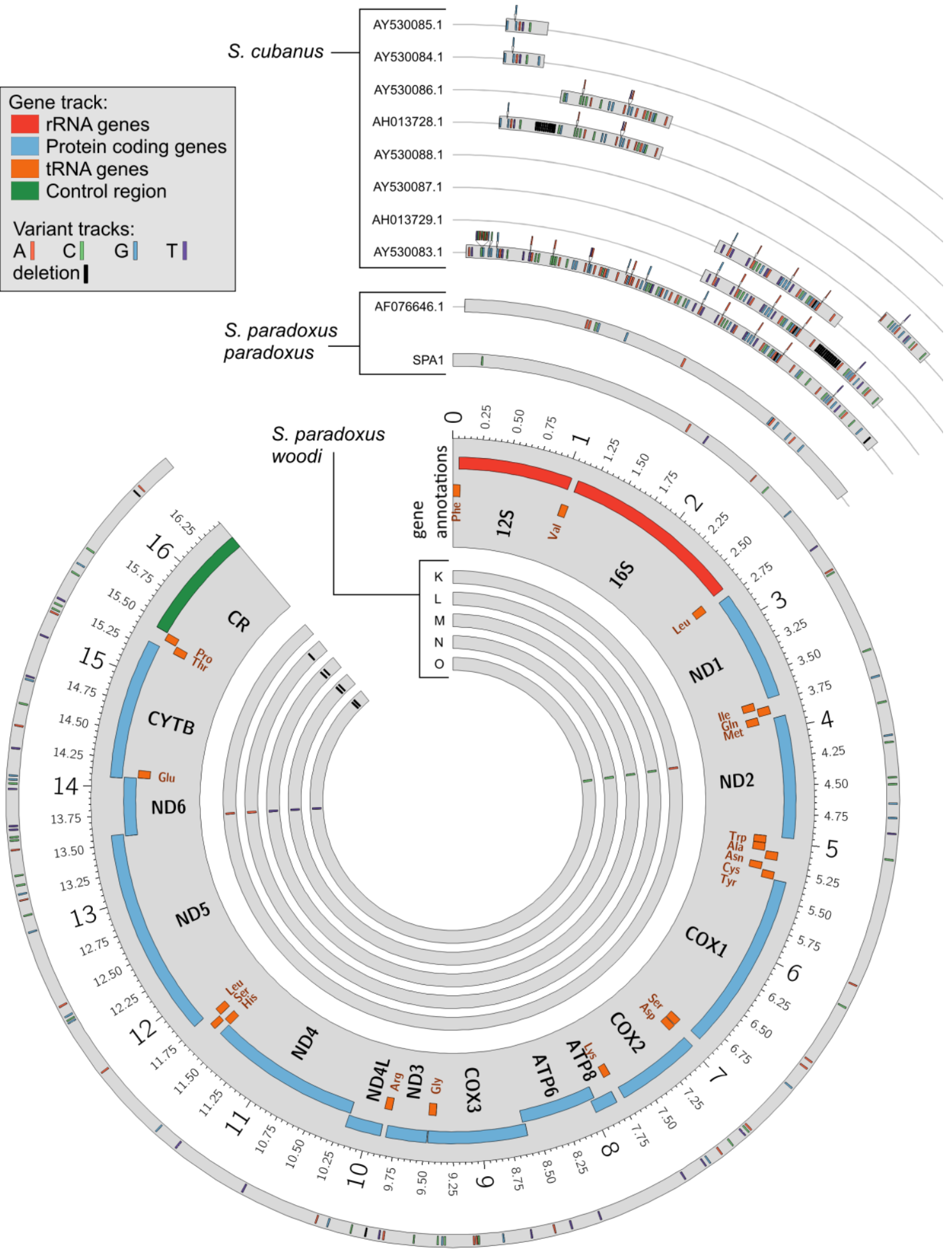
This is an Accepted Manuscript of an article published by Taylor \& Francis Group in Mitochondrial DNA Part A on 15/03/2016, available online: http://dx.doi.org/10.3109/24701394.2016.1167891.

(A)

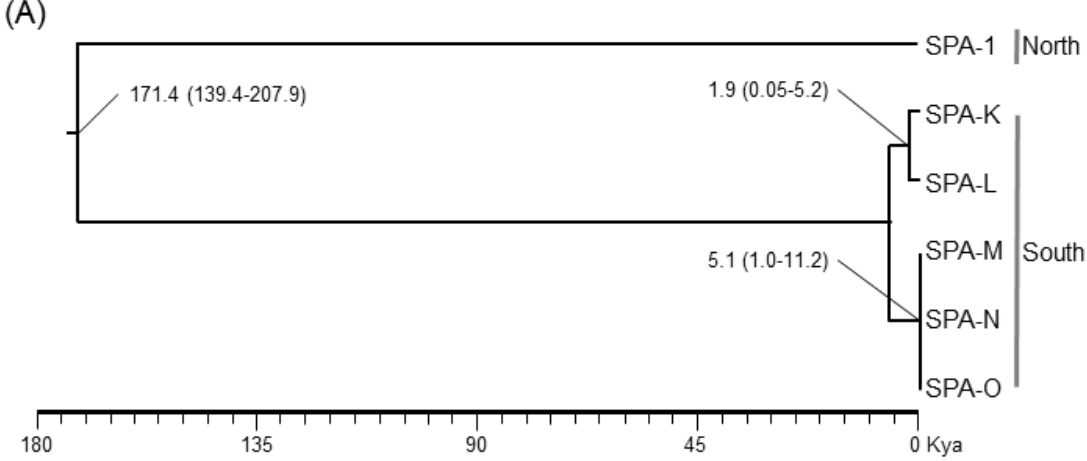

(B)

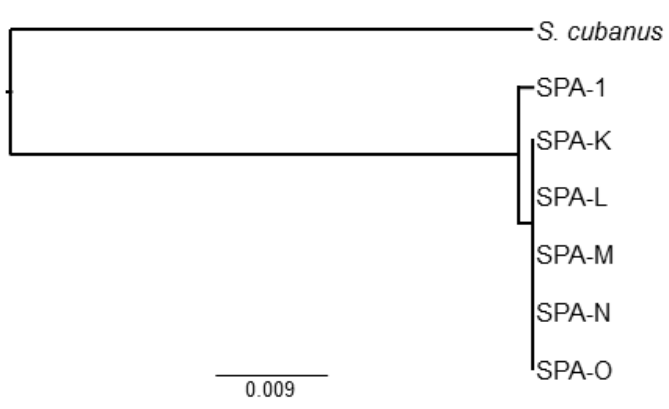

(C)

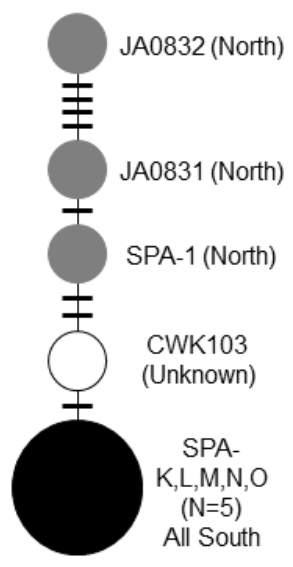


This is an Accepted Manuscript of an article published by Taylor \& Francis Group in Mitochondrial DNA Part A on 15/03/2016, available online: http://dx.doi.org/10.3109/24701394.2016.1167891.

624 Table 1. Provenance of Solenodon paradoxus samples

\begin{tabular}{|c|c|c|c|c|c|c|c|c|c|}
\hline \multirow{2}{*}{$\frac{\text { ID }}{\text { SPA-K }}$} & \multirow{2}{*}{$\begin{array}{c}\text { Region } \\
\text { South }\end{array}$} & \multirow{2}{*}{$\begin{array}{l}\text { Province } \\
\text { Pedernales }\end{array}$} & \multirow{2}{*}{$\begin{array}{l}\text { Locality } \\
\text { La Cañada del Verraco }\end{array}$} & \multicolumn{3}{|c|}{ Sex Collected Weight (g) } & \multicolumn{2}{|c|}{ Coordinates } & \multirow[t]{2}{*}{ Sequences } \\
\hline & & & & M & Wild & 579 & N 18 $09^{\prime} 9.64^{\prime \prime}$ & $\mathrm{W} 71^{\circ}$ & \\
\hline SPA-L & South & Pedernales & La Cañada del Verraco & M & Wild & 1020 & N 1809' 9.64" & $\mathrm{W} 71^{\circ}$ & "This study \\
\hline SPA-M & South & Pedernales & El Manguito - 1 & $\mathrm{M}$ & Wild & 1270 & N 18० 06' 36.6” & $\mathrm{W} 71^{\circ}$ & "This study \\
\hline SPA-N & South & Pedernales & El Manguito - 1 & $\mathrm{~F}$ & Wild & 1420 & N 18 $06^{\prime} 36.6^{\prime \prime}$ & $\mathrm{W} 71^{\circ}$ & "This study \\
\hline SPA-O & South & Pedernales & El Manguito - 2 & $\mathrm{~F}$ & Wild & 1120 & N $18^{\circ} 07^{\prime} 6.5^{\prime \prime}$ & W $71^{\circ}$ & "This study \\
\hline SPA-1 & North & Espaillat & Cordillera Septentrional & $\mathrm{M}$ & Zoo* & - & - & - & This study \\
\hline JA0832 & North & Maria Trinidad Sanchez & Loma de la Jagua & - & - & - & - & - & Allard et al. 2001 \\
\hline JA0831 & North & Maria Trinidad Sanchez & Loma de la Jagua & - & - & - & - & - & Allard et al. 2001 \\
\hline \multicolumn{3}{|c|}{ CWK103 Unknown - } & - & - & - & - & - & - & Allard et al. 2001 \\
\hline
\end{tabular}




\title{
Mitogenomic sequences support a north-south subspecies subdivision within Solenodon paradoxus
}

\author{
Supplementary Material
}

Authors: Adam L. Brandt ${ }^{1,2+}$, Kirill Grigorev ${ }^{4+}$, Yashira M. Afanador-Hernández ${ }^{4}$, Liz A. Paulino $^{5}$, William J. Murphy ${ }^{6}$, Adrell Núñez ${ }^{7}$, Aleksey Komissarov ${ }^{8}$, Jessica R. Brandt ${ }^{1}$, Pavel Dobrynin $^{8}$, J. David Hernández-Martich ${ }^{9}$, Roberto María ${ }^{7}$, Stephen J. O’Brien ${ }^{8,10}$, Luis E. Rodríguez $^{5}$, Juan C. Martínez-Cruzado ${ }^{4}$, Taras K. Oleksyk ${ }^{4 *}$ and Alfred L. Roca ${ }^{1,2,3 *}$

${ }^{+}$Equal contributors

*Corresponding authors: roca@illinois.edu; taras.oleksyk@upr.edu

Affiliations: ${ }^{1}$ Department of Animal Sciences, ${ }^{2}$ Illinois Natural History Survey and ${ }^{3}$ Carl R. Woese Institute for Genomic Biology, University of Illinois at Urbana-Champaign, Urbana, IL 61801; ${ }^{4}$ Department of Biology, University of Puerto Rico at Mayagüez, Mayagüez, Puerto Rico 00681; ${ }^{5}$ Instituto Tecnológico de Santo Domingo (INTEC), Santo Domingo, Dominican Republic; ${ }^{6}$ Department of Veterinary Integrative Biosciences, Texas A\&M University, College Station, TX 77843; ${ }^{7}$ Department of Conservation and Science, Parque Zoológico Nacional (ZOODOM), Santo Domingo, Dominican Republic; ${ }^{8}$ Theodosius Dobzhansky Center for Genome Bioinformatics, St. Petersburg State University, 199004 St. Petersburg, Russia; ${ }^{9}$ Instituto de Investigaciones Botanicas y Zoologicas, Universidad Autónoma de Santo Domingo, Santo Domingo, Dominican Republic; ${ }^{10}$ Oceanographic Center, Nova Southeastern University, Fort Lauderdale, Florida 33004 
Figure S1. Relationship of solenodon mitochondrial genomes to those of other mammals. The maximum likelihood tree of laurasiatherian mammals showing the position of solenodons was generated in RAxML version 8.2.4 (Stamatakis 2014), using the GTR $+\mathrm{I}+\mathrm{G}$ substitution model and 1000 rapid bootstrap replicates. Full mitochondrial genome sequences (excluding control region and regions of poor alignment) from the taxa on the tree were used to generate the phylogeny. Letters indicate the nodes for which fossil calibration dates and inferred molecular dates are described in Table S3. 


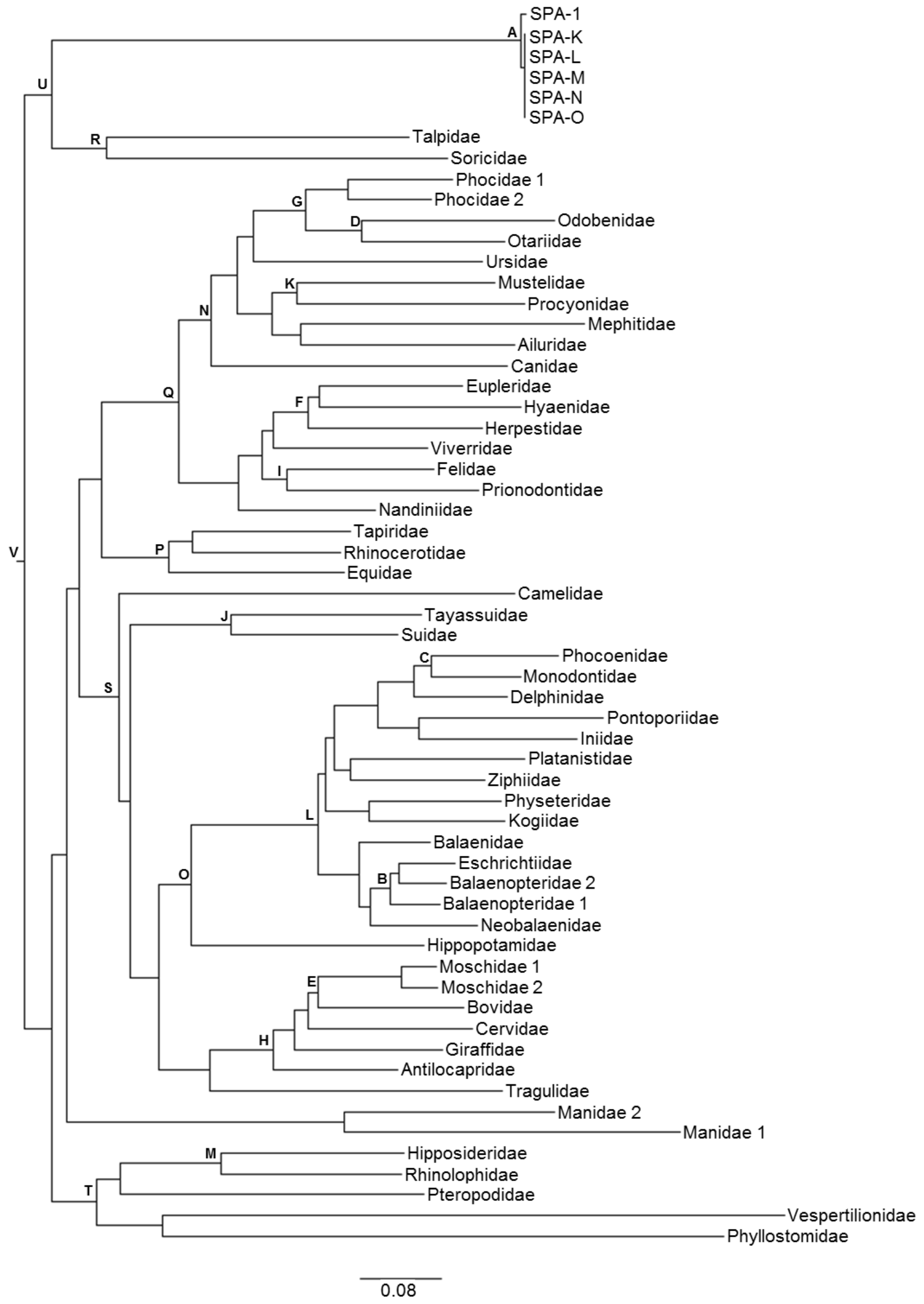


Figure S2. Phylogeny of laurasiatherian mammals showing the position of Solenodon paradoxus. The tree was generated using the full mitogenome sequences except that regions of poor alignment were excluded, as was the control region, which is unreliable for the deep time scales involved (Ingman et al. 2000). The relationships among taxa were not constrained to those established using the fossil record or nuclear genetic relationships, since in some circumstances mitogenomic relationships may be incongruent with the true species tree (Petit and Excoffier 2009). For molecular dating, previously well-established fossil calibrations (Meredith et al. 2011) were incorporated into an analysis conducted using the software BEAST v1.8.2 software (Drummond et al. 2012). At eulipotyphlan nodes, the Bayesian posterior probability and maximum likelihood bootstrap support are listed above, while below are listed dates of divergence with $95 \%$ credibility intervals in parentheses. The time at which the solenodon mitogenome diverged from that of other mammals was estimated as 78.2 Mya (95\% CI: 62.198.6 Mya). The point estimate for the divergence time between solenodons and other mammals is similar to previous estimates ranging from 73-76 Mya, based upon analysis of datasets largely comprised of nuclear sequences (Roca et al. 2004, Meredith et al. 2011). 


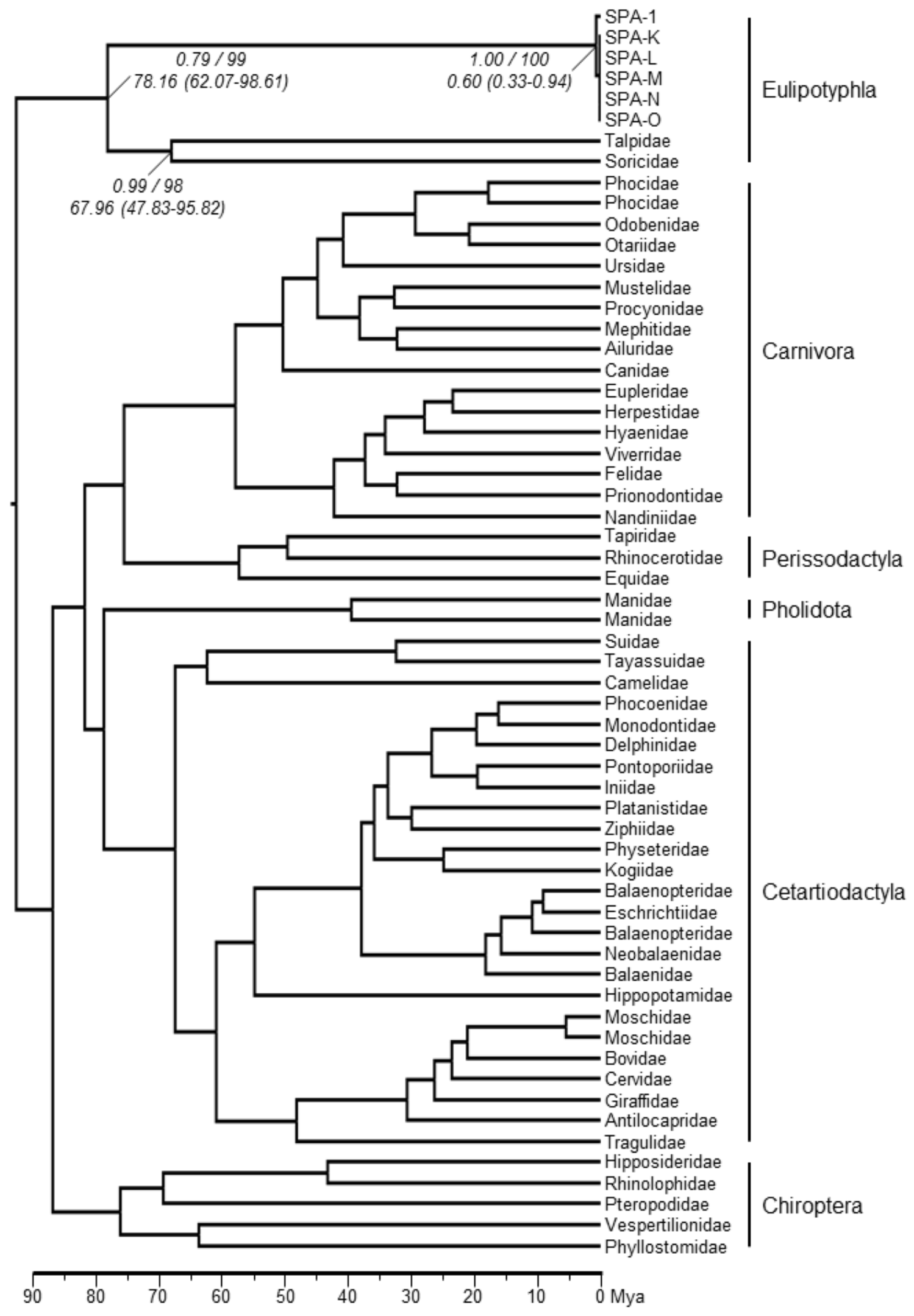



available online: http://dx.doi.org/10.3109/24701394.2016.1167891.

Table S1. Radical mutations in mitochondrial protein coding genes of $S$. paradoxus in comparison to those of reference species. Mutations are shown in this format: position, amino acid in the reference mitogenome, amino acid in S. paradoxus. Scores were calculated with PROVEAN using a stringent threshold for listing the radical mutations of -4.1 . Entries are vertically aligned with regard to preceding insertion and deletion events.

Gene $\quad$ Reference species

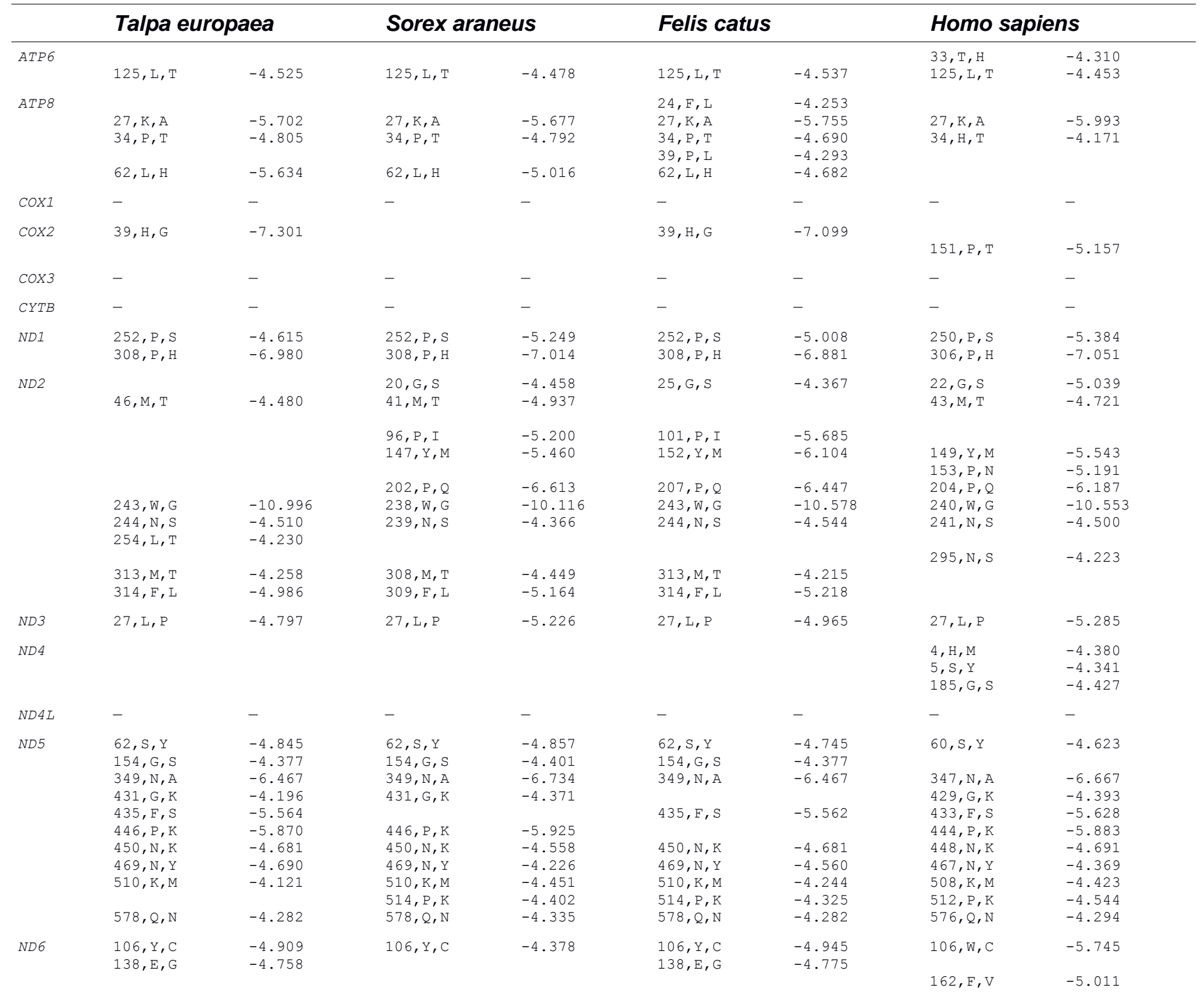


Table S2. Taxa used for comparison of S. paradoxus to other mammals.

\begin{tabular}{|c|c|c|c|}
\hline Order & Family & Taxon & $\begin{array}{l}\text { GenBank } \\
\text { accession code }\end{array}$ \\
\hline Eulipotyphla & Solenodontidae & SPA-1 & KU697358 \\
\hline Eulipotyphla & Solenodontidae & SPA-K & KU697359 \\
\hline Eulipotyphla & Solenodontidae & SPA-L & KU697360 \\
\hline Eulipotyphla & Solenodontidae & SPA-M & KU697361 \\
\hline Eulipotyphla & Solenodontidae & SPA-N & KU697362 \\
\hline Eulipotyphla & Solenodontidae & SPA-O & KU697363 \\
\hline Eulipotyphla & Soricidae & European shrew & NC_027963 \\
\hline Eulipotyphla & Talpidae & European mole & NC_002391 \\
\hline Cetartiodactyla & Antilocapridae & Pronghorn & NC_020679 \\
\hline Cetartiodactyla & Balaenidae & Southern right whale & NC_006930 \\
\hline Cetartiodactyla & Balaenopteridae 1 & Pygmy Bryde's whale & NC_007938 \\
\hline Cetartiodactyla & Balaenopteridae 2 & Humpback whale & NC_006927 \\
\hline Cetartiodactyla & Bovidae & Domestic cattle & NC_006853 \\
\hline Cetartiodactyla & Camelidae & Bactrian camel & NC_009628 \\
\hline Cetartiodactyla & Cervidae & Reindeer & NC_007703 \\
\hline Cetartiodactyla & Delphinidae & Heaviside's dolphin & NC_020696 \\
\hline Cetartiodactyla & Eschrichtiidae & Grey whale & NC_005270 \\
\hline Cetartiodactyla & Giraffidae & Giraffe & NC_024820 \\
\hline Cetartiodactyla & Hippopotamidae & Pygmy hippopotamus & NC_020697 \\
\hline Cetartiodactyla & Iniidae & Amazon river dolphin & NC_005276 \\
\hline Cetartiodactyla & Kogiidae & Pygmy sperm whale & NC_005272 \\
\hline Cetartiodactyla & Monodontidae & Narwhal & NC_005279 \\
\hline Cetartiodactyla & Moschidae 1 & Anhui musk deer & NC_020017 \\
\hline Cetartiodactyla & Moschidae 2 & Siberian musk deer & NC_013753 \\
\hline Cetartiodactyla & Neobalaenidae & Pygmy right whale & NC_005269 \\
\hline Cetartiodactyla & Phocoenidae & Finless porpoise & NC_026456 \\
\hline Cetartiodactyla & Physeteridae & Sperm whale & NC_002503 \\
\hline Cetartiodactyla & Platanistidae & Indus River dolphin & NC_005275 \\
\hline Cetartiodactyla & Pontoporiidae & La Plata dolphin & NC_005277 \\
\hline Cetartiodactyla & Suidae & Domestic pig & NC_000845 \\
\hline Cetartiodactyla & Tayassuidae & Collared peccary & NC_012103 \\
\hline Cetartiodactyla & Tragulidae & Water chevrotain & NC_020714 \\
\hline Cetartiodactyla & Ziphiidae & Ginkgo-toothed beaked whale & NC_027593 \\
\hline Perissodactyla & Equidae & Horse & NC_001640 \\
\hline Perissodactyla & Rhinocerotidae & White rhinoceros & NC_001808 \\
\hline Perissodactyla & Tapiridae & Malayan tapir & NC_023838 \\
\hline Carnivora & Ailuridae & Red panda & NC_009691 \\
\hline Carnivora & Canidae & Domestic dog & NC_002008 \\
\hline
\end{tabular}


Table S2. Continued.

\begin{tabular}{llll}
\hline Order & Family & Taxon & $\begin{array}{l}\text { GenBank } \\
\text { accession code }\end{array}$ \\
\hline Carnivora & Eupleridae & Narrow-striped mongoose & NC_027828 \\
Carnivora & Felidae & Domestic cat & NC_001700 \\
Carnivora & Herpestidae & Indian mongoose & NC_006835 \\
Carnivora & Hyaenidae & Spotted hyena & NC_020670 \\
Carnivora & Mephitidae & Striped skunk & NC_020648 \\
Carnivora & Mustelidae & American marten & NC_020642 \\
Carnivora & Nandiniidae & African palm civet & NC_024567 \\
Carnivora & Odobenidae & Atlantic walrus & NC_004029 \\
Carnivora & Otariidae & California sea lion & NC_008416 \\
Carnivora & Phocidae 1 & Harp seal & NC_008429 \\
Carnivora & Phocidae 2 & Weddell seal & NC_008424 \\
Carnivora & Prionodontidae & Spotted linsang & NC_024569 \\
Carnivora & Procyonidae & Raccoon & NC_009126 \\
Carnivora & Ursidae & Giant short-faced bear & NC_011116 \\
Carnivora & Viverridae & Servaline genet & NC_024568 \\
Chiroptera & Hipposideridae & Great roundleaf bat & NC_018540 \\
Chiroptera & Phyllostomidae & Common vampire bat & NC_022423 \\
Chiroptera & Pteropodidae & Large flying fox & NC_026542 \\
Chiroptera & Rhinolophidae & Big-eared horseshoe Bat & NC_026460 \\
Chiroptera & Vespertilionidae & Red bat & NC_016873 \\
Pholidota & Manidae 1 & Tree pangolin & NC_026780 \\
Pholidota & Manidae 2 & Malayan pangolin & NC_026781 \\
\hline
\end{tabular}



http://dx.doi.org/10.3109/24701394.2016.1167891.

Table S3. Laurasiatherian fossil calibration dates and inferred molecular dating.

\begin{tabular}{|c|c|c|c|c|c|}
\hline Group & Node & Fossil $^{\star}$ & Estimated $(95 \% \mathrm{Cl})$ & $\begin{array}{l}\text { Posterior } \\
\text { probability }\end{array}$ & $\begin{array}{c}\text { Bootstrap } \\
\text { node support } \\
(\%)\end{array}$ \\
\hline Base of S. paradoxus & $A$ & - & $0.60(0.33-0.94)$ & 1.00 & 100 \\
\hline Megaptera-Eschrichtius & B & 7.3-23.03 & $10.74(7.69-14.02)$ & 1.00 & 100 \\
\hline Phocoenidae-Monodontidae & C & $12.1-28.5$ & $16.10(11.52-20.40)$ & 1.00 & 100 \\
\hline Otariidae-Odobenidae & $\mathrm{D}$ & $15.97-34$ & $20.84(15.83-25.67)$ & 1.00 & 100 \\
\hline Bovidae-Moschidae & $E$ & $18-34$ & $21.05(16.49-25.54)$ & 1.00 & 31 \\
\hline Herpestidae-Eupleridae & $\mathrm{F}$ & $15.97-34$ & $23.43(18.44-28.85)$ & 1.00 & 100 \\
\hline Phocidae-(Otariidae+Odobenidae) & G & $20.43-34$ & $29.36(24.93-34.06)$ & 1.00 & 100 \\
\hline Giraffidae-Antilocapridae & $\mathrm{H}$ & $17.8-34$ & $30.55(25.80-35.39)$ & 1.00 & 100 \\
\hline Felidae-Prionodontidae & 1 & $28.3-40.6$ & $32.27(27.29-37.10)$ & 1.00 & 99 \\
\hline Suidae-Tayassuidae & $J$ & $15.97-37.3$ & 32.37 (35.55-41.13) & 1.00 & 100 \\
\hline Procyonidae-Mustelidae & $\mathrm{K}$ & $27.6-40.6$ & 32.61 (27.50-37.43) & 1.00 & 96 \\
\hline Cetacea & $\mathrm{L}$ & $33.8-48.8$ & $37.80(33.27-42.18)$ & 1.00 & 100 \\
\hline Hipposideridae-Rhinolophidae & M & $37.1-56$ & $43.28(34.18-52.18)$ & 1.00 & 100 \\
\hline Canidae-Arctoidea & $\mathrm{N}$ & $37.1-56$ & $50.38(45.25-55.75)$ & 1.00 & 100 \\
\hline Whippomorpha & $\mathrm{O}$ & $52.5-61.1$ & $54.80(50.85-58.73)$ & 1.00 & 100 \\
\hline Base of Perissodactyla & $\mathrm{P}$ & $55.5-61.1$ & $57.33(54.11-60.58)$ & 1.00 & 100 \\
\hline Base of Carnivora & $\mathrm{Q}$ & $37.1-65.8$ & 57.78 (52.11-63.57) & 1.00 & 100 \\
\hline Talpidae-Soricidae & $\mathrm{R}$ & - & 67.96 (47.83-95.82) & 0.99 & 98 \\
\hline Base of Cetartiodactyla & $S$ & $52.5-65.8$ & $67.46(52.67-72.57)$ & 1.00 & 100 \\
\hline Base of Chiroptera & $\mathrm{T}$ & - & 76.09 (66.57-85.48) & 1.00 & 100 \\
\hline Base of Eulipotyphla & $\mathrm{U}$ & - & 78.16 (62.07-98.61) & 0.79 & 99 \\
\hline Base of Laurasiatheria & $\mathrm{V}$ & - & $92.61 \quad(80.06-119.48)$ & 1.00 & - \\
\hline
\end{tabular}

*Fossil calibration dates are as described previously (Meredith et al. 2011). 


\section{Supplementary References}

Drummond AJ, Suchard MA, Xie D, Rambaut A. 2012. Bayesian phylogenetics with BEAUti and the BEAST 1.7. Mol Biol Evol. 29:1969-1973.

Ingman M, Kaessmann H, Paabo S, Gyllensten U. 2000. Mitochondrial genome variation and the origin of modern humans. Nature. 408:708-713.

Meredith RW, Janecka JE, Gatesy J, Ryder OA, Fisher CA, Teeling EC, Goodbla A, Eizirik E, Simao TL, Stadler T, et al. 2011. Impacts of the Cretaceous Terrestrial Revolution and KPg extinction on mammal diversification. Science 334:521-524.

Petit RJ, Excoffier L. 2009. Gene flow and species delimitation. Trends Ecol Evol. 4:386-393.

Roca AL, Bar-Gal GK, Eizirik E, Helgen KM, Maria R, Springer MS, O'Brien SJ, Murphy WJ. 2004. Mesozoic origin for West Indian insectivores. Nature 429:649-651.

Stamatakis A. 2014. RAxML version 8: a tool for phylogenetic analysis and post-analysis of large phylogenies. Bioinformatics. 30:1312-1313. 